\title{
Electrophysiological study of amyotrophy associated with acute asthma (asthmatic amyotrophy)
}

\author{
G. DANTA ${ }^{1}$ \\ From the Staffordshire General Infirmary, Stafford, \\ and the North Staffordshire Hospital Centre, Stoke-on-Trent
}

SYNOPSIS A girl developed acute amyotrophy of the left arm five days after onset of an acute attack of bronchial asthma. Slow improvement in muscle power began nine months later. There was severe denervation with preservation of sensation and normal motor nerve conduction velocities when these were measurable. The patient is similar to 10 patients reported by Hopkins (1974).

Hopkins and Shield (1974) reported-and subsequently Hopkins (1974) described in greater detail-10 asthmatic children who developed asymmetrical weakness and wasting of limb muscles four to seven days after an acute attack of asthma. The condition resembled acute paralytic poliomyelitis, but all patients had been immunized with Salk or Sabin vaccine and there was no rise in poliovirus antibody titre in sera of seven patients. None of the many drugs given for asthma could convincingly be held responsible for the amyotrophy.

Electrophysiological studies were carried out on two patients. One had severe weakness of the right leg, proximal weakness of the left leg, and mild weakness of the left arm. Motor conduction velocity in the left ulnar nerve was reduced to $44 \mathrm{~m} / \mathrm{s}$, but was normal $(50 \mathrm{~m} / \mathrm{s})$ in the ulnar nerve of the unaffected arm. The other patient had paresis and areflexia of the right leg and slight weakness of the left leg. Motor conduction velocity of 'relevant' nerves was normal, but the amplitude of evoked motor responses was 'markedly diminished'. The amplitudes of sensory potentials of nerves not specified by the author were normal.

The clinical and electrophysiological findings in a child similar to the patients reported by Hopkins (1974) will be described.

1 Address for correspondence: Neurology Department, Woden Valley Hospital, PO Box 11, Woden ACT 2606, Australia.

(Accepted 12 May 1975.)

\section{CASE HISTORY}

K.W. (SGI 197958), an 8 year old girl, was delivered $\underset{\infty}{\omega}$ normally at term; birth weight $3.5 \mathrm{~kg}$. Development $\vec{\circ}$ proceeded normally and she suffered no serious i i nesses until the onset of bronchial asthma at the age of 4 years 3 months. The following immunizations had been carried out: course of three injections for diphtheria, tetanus, and whooping cough complete at 7 months; poliomyelitis Sabin vaccine at 6 , \$, and 8 months and a booster dose at 18 month: smallpox vaccine at 19 months. Further booster dos for diphtheria, tetanus, and poliomyelitis were nêt given because of the asthma.

Her father and 14 year old brother suffered from bronchial asthma. Her sister, aged 4 years, was well, but another sib, the second child, born prematurely, died of pneumonia at 10 days. There was no neurological or other medical disease in the family.

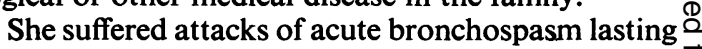
up to 12 hours about every two to three months, $\overrightarrow{\overrightarrow{0}}$ necessitating frequent hospital admissions. In be- 3 tween attacks she had briefer, milder, nocturnal as well as diurnal episodes, sometimes as often as twice a week. The following drugs had been given $\overline{\overline{3}}$ to her at varying times: orciprenaline sulphate, theo- phylline, ephedrine hydrochloride, phenobarbitone, 0 prednisolone, adrenaline hydrochloride, sodium cromoglycate, salbutamol, and isoprenaline sulphate. $\delta$ She attended hospital rather irregularly and at times her father administered to her his own anti-asthma윽 medications, including steroids. Skin sensitivity to the following allergens was demonstrated at the age을 of 5 years: A1 mixed inhalants (house dust, feathers, horse dander and hair, cat fur, dog hair, orris), $A 12^{\circ}$ pollens (B1 shrubs, B2 grasses, B3 trees), and Dermo- $N$ 
Electrophysiological study of amyotrophy associated with acute asthma (asthmatic amyotrophy) 1017

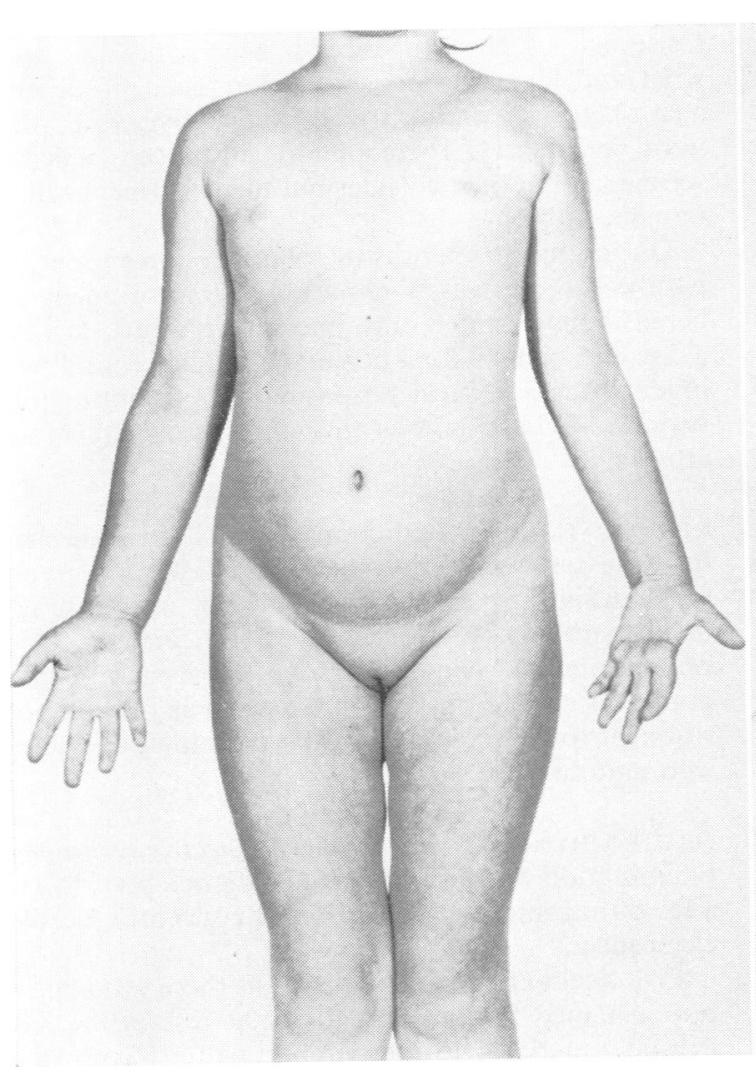

(a)

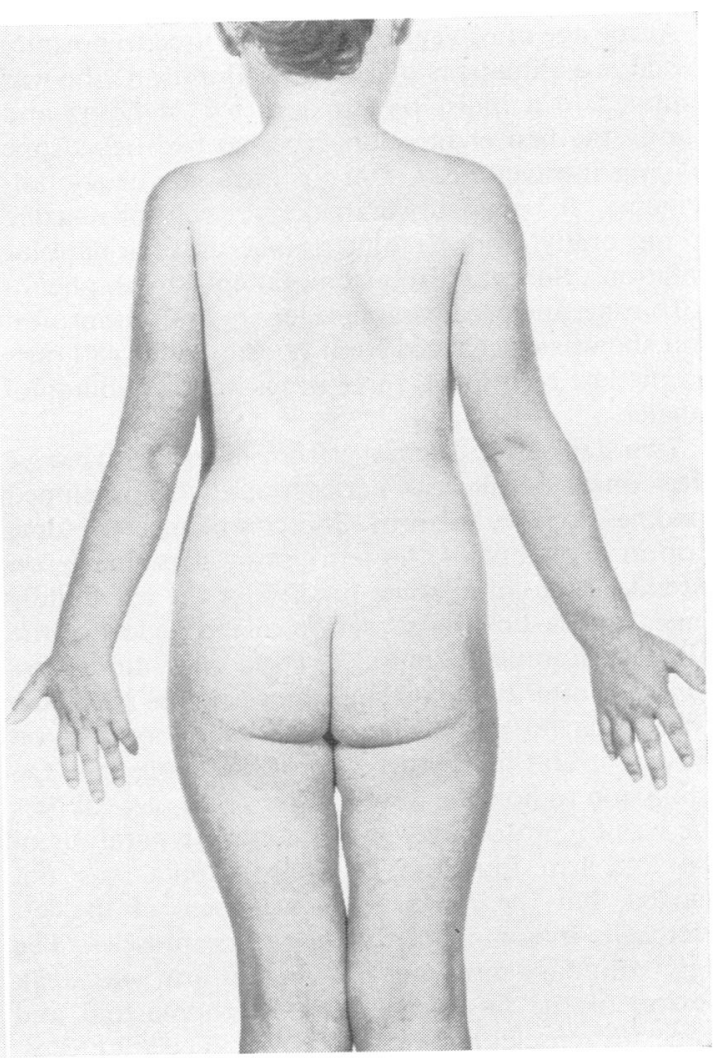

(b)

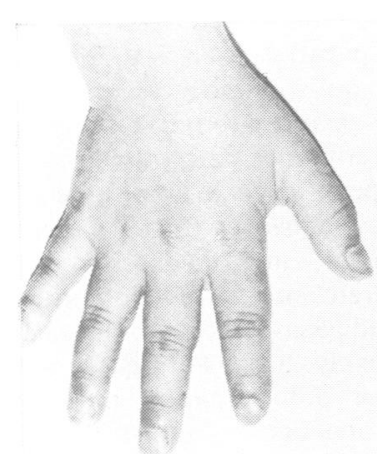

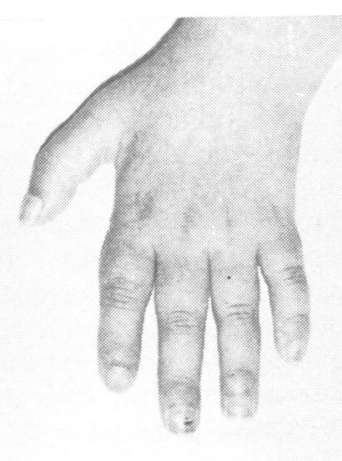

(c)

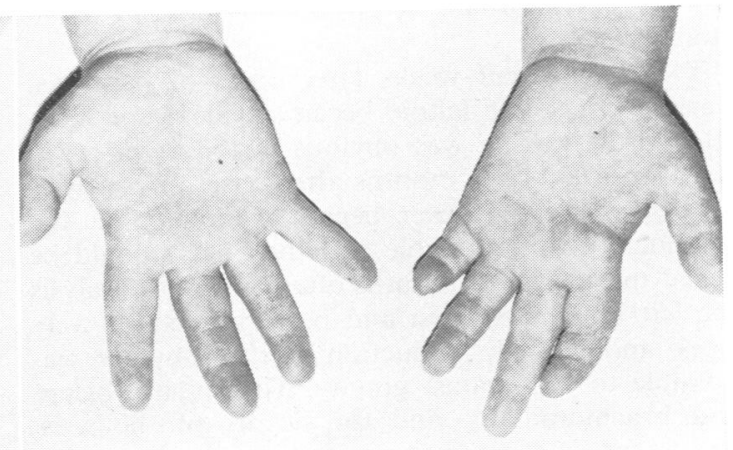

(d)

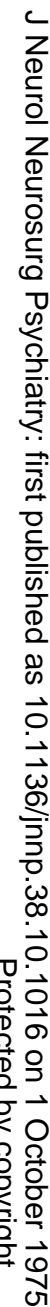

ơ

ํํำ 
graphia farinae (Bencard skin test reactions). At no time was a significant eosinophilia found.

At the age of $6 \frac{1}{2}$ years she was admitted to hospital in status asthmaticus of $\mathbf{1 7}$ hours' duration. She was confined to a moist oxygen tent for 24 hours and during the first eight hours received hydrocortisone $500 \mathrm{mg}$ intravenously, $100 \mathrm{mg}$ intramuscularly, adrenaline $0.7 \mathrm{mg}$ subcutaneously, chlorpromazine $45 \mathrm{mg}$ orally, and beclomethasone dipropionate inhalations. She was also given oral ephedrine, phenobarbitone, and prednisolone. Her breathing improved and she was discharged from hospital after 48 hours on the last mentioned three drugs and a salbutamol inhaler.

Two days after discharge from hospital, five days after onset of the asthmatic attack, she developed weakness of the left arm. She complained of some pain at the front of the left elbow, particularly on extending the joint, some tingling of the left middle finger, and a tickling sensation in the region of the left brachioradialis muscle. These sensations disappeared after two days, but the weakness persisted. There was no pain in the neck or discomfort on moving it and no disturbance of consciousness. On admission to hospital a week after onset of weakness she was found to have almost complete paralysis of the left arm muscles. The left scapula was not winged, but there was some weakness of the left pectoralis major and latissimus dorsi muscles. The only voluntary movement of the left arm was weak flexion of the fingers. The left sternomastoid and trapezius muscles had normal power. The left biceps, supinator, and triceps reflexes were absent. The paralysed muscles felt flabby but were not tender. Muscle power and tendon reflexes were normal in the other three limbs, and the abdominal and plantar reflexes were normal. Sensation was normal to all modalities.

Two and a half weeks after onset of paralysis, wasting of the left deltoid became evident and soon afterwards wasting was obvious in the other paralysed muscles. Nine months after onset of paralysis slow recovery of power began. Abduction at the shoulder became possible and the fingers could be flexed more. Eleven months after onset of paralysis the left latissimus dorsi and pectoralis major were weak and wasted. Abduction at the shoulder was possible to $70^{\circ}$ against gravity. The spinati, biceps and brachioradialis, and the flexors of the wrist and fingers had regained some power, but extension at elbow, wrist, and of the fingers was impossible against gravity. The triceps reflex was absent, but the supinator and biceps reflexes were present though diminished compared with their counterparts. There was no sensory abnormality. Nineteen months after onset of paralysis wasting of the muscles persisted
(Fig. 1), but abduction at the left shoulder against gravity was now $90^{\circ}$. There was contraction against resistance of the left biceps, brachioradialis and wrist and finger flexors, but incomplete movement against gravity of the triceps and extensors of the wrist and fingers. The supinator and biceps reflexes were equal on the two sides but the left triceps reflex remained absent.

During the 19 months of follow-up after onset of paralysis there was a remarkable improvement in her asthmatic state: only one severe attack lasting $\stackrel{\vec{\rho}}{\stackrel{5}{\sigma}}$ a day and necessitating hospital attendance, and two $\bar{c}$ milder attacks of bronchospasm occurred during this period. Medication was given only for individual attacks.

INVESTIGATIONS Blood count, ESR, liver and renal function tests were normal. The chest radiograph was normal and showed no evidence of diaphragmatic paralysis. Radiographs of the cervical spine were normal. A year after onset of paralysis a myelogram was carried out and this, as well as the composition of the CSF, were normal. Virological studies $\underset{\infty}{\omega}$ were not done.

ELECTROPHYSIOLOGICAL STUDIES Electromyograph Examination was limited by the patient's poor toles ance of intramuscular insertion of concentric need 8 electrodes.

Five weeks after onset of paralysis there was scantoy but sustained fibrillation activity at rest in the le

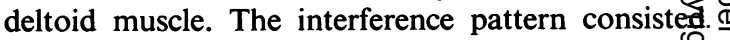
of few discrete low-amplitude motor unit potentias of normal configuration. In the left first dorsal inter- ov osseous muscle there was no spontaneous electrical activity at rest and when the muscle was contracted small amplitude muscle potentials were seen.

Eleven months after paralysis the left supraspinatus muscle showed no spontaneous activity. Contraction of the muscle gave rise to normal motor $\varrho$ unit potentials and the interference pattern was only $\overrightarrow{\vec{O}}$ slightly incomplete with peak-to-peak amplitude of 3 $2 \mathrm{mV}$. In the left deltoid and triceps muscles there was no spontaneous activity, and the interference? patterns consisted of discrete motor unit potentials of normal configuration and peak-to-peak amplitudes $\frac{5}{0}$ of 0.2 and $1.5 \mathrm{mV}$, respectively. In the left first dorsal $\dot{0}$ interosseous and abductor pollicis brevis muscles 3 there was increased insertional activity and sustained $\delta$ fibrillation activity at rest. Small amplitude discrete $§$ motor unit potentials of normal configuration were $\mathrm{O}$ seen on contraction of the muscles, the peak-to-peak voltage not exceeding $100 \mu \mathrm{V}$.

Nineteen months after paralysis the left extensor and flexor digitorum muscles showed no spontaneous $\sigma$ electrical activity. Motor unit potentials of normal N 
configuration were seen and the interference patterns consisted of discrete unit potentials with maximal peak-to-peak amplitude of 1.5 and $1.0 \mathrm{mV}$, respectively. In the left biceps there was again no spontaneous activity, but many polyphasic potentials were seen on contraction of the muscle. The interference pattern was incomplete with a large triphasic unit potential measuring $15 \mathrm{mV}$ standing out from the background pattern. Occasional but sustained fibrillation potentials were seen in the left first dorsal interosseous and abductor pollicis brevis muscles. The interference patterns were incomplete but the motor unit potentials were of normal configuration. In the abductor pollicis brevis the peak-to-peak amplitude was $300 \mu \mathrm{V}$ but in the left first dorsal interosseous muscle a single unit measuring $5 \mathrm{mV}$ in amplitude stood out from the background pattern.

Nerve conduction studies The patient was examined five weeks and 11,12, and 19 months after onset of paralysis. Results of motor and sensory nerve conduction studies are given in Table 1.

Spinal and cortical evoked responses A DISA 14A21 electromyograph was used together with a DISA 14G01 averager. The median nerves were stimulated percutaneously at the wrist with a stimulus of $0.2 \mathrm{~ms}$ duration and of supramaximal voltage for the motor response. Recording electrodes were SLE B1 silver/ silver chloride stick-on electrodes. For the cortical evoked potentials the anode was placed $7 \mathrm{~cm}$ lateral to and $2 \mathrm{~cm}$ behind the mid-point joining the nasion to the inion and for the cervical evoked potentials just above the second $\left(C_{2}\right)$ and below the sixth $\left(C_{6}\right)$ cervical spinous processes. In each case, the anode was placed $30 \%$ of the distance between the nasion and the inion behind the former. The resistance of the surface electrodes was below $3 \mathrm{k} \mathrm{ohm} .128$ cortical evoked responses, 0.4 to $100 \mathrm{~ms}$ after the stimulus, and 256 spinal evoked potentials, 0.4 to $50 \mathrm{~ms}$ after the stimulus were averaged. The rate of stimulation was $0.5 \mathrm{~Hz}$ for the cortical and $1.0 \mathrm{~Hz}$ for the spinal evoked potentials.

The patient was examined 11 and 19 months after onset of paralysis. The findings on both occasions were similar and are given in Table 2 and Fig. 2.

\section{DISCUSSION}

The clinical picture of the 10 patients described by Hopkins (1974) and the present case is uniform. All patients were asthmatics aged 2 to 8 years. Amyotrophy commenced suddenly four to seven days after a severe attack of asthma.

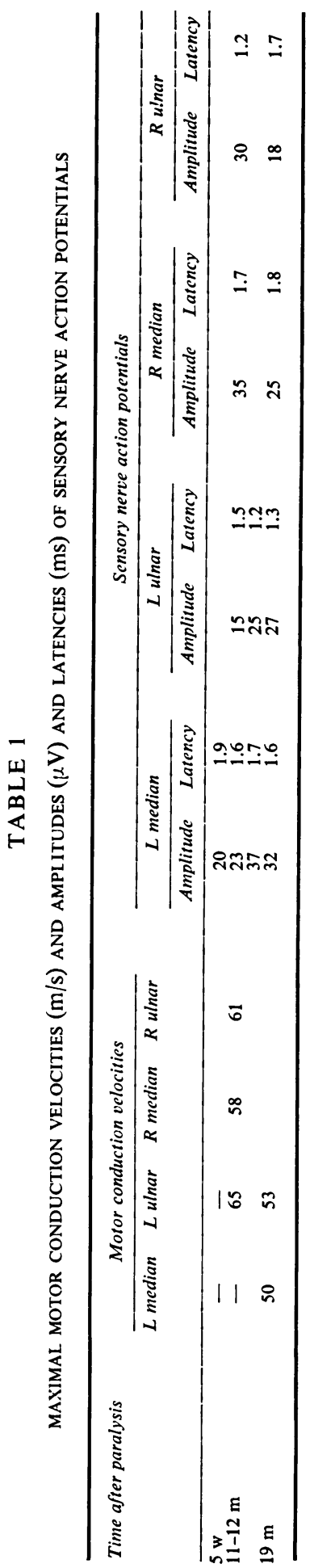


TABLE 2

AMPLITUDE AND LATENCY OF INITIAL NEGATIVE SOMATOSENSORY CORTICAL $\left(\mathrm{C}_{\mathrm{x}}\right)$ AND CERVICAL $\left(\mathrm{C}_{2}\right.$ AND $\left.\mathrm{C}_{6}\right)$ EVOKED RESPONSES WITH STIMULATION OF $R$ AND $L$ MEDIAN NERVES AT WRIST

\begin{tabular}{|c|c|c|c|c|c|c|}
\hline \multirow{4}{*}{$\begin{array}{c}\mathbf{R} \text { median } \\
\mathbf{C}_{\mathbf{x}} \\
\mathbf{C}_{2} \\
\mathbf{C}_{\mathbf{B}}\end{array}$} & \multicolumn{2}{|c|}{ Amplitude $(\mu V)$} & \multicolumn{2}{|c|}{ Latency (ms) } & \multicolumn{2}{|c|}{ Latency to peak $(\mathrm{ms})$} \\
\hline & & & & & & \\
\hline & $\begin{array}{l}7.2 \\
5.2\end{array}$ & $\begin{array}{l}5.2 \\
6.7\end{array}$ & $\begin{array}{r}13.5 \\
7.2\end{array}$ & $\begin{array}{r}13.0 \\
7.7\end{array}$ & $\begin{array}{r}16.9 \\
9.4\end{array}$ & $\begin{array}{r}14.9 \\
9.8\end{array}$ \\
\hline & 5.7 & 5.7 & 6.7 & 6.8 & 9.2 & 8.7 \\
\hline \multicolumn{7}{|l|}{$\mathrm{L}$ median } \\
\hline$C_{x}$ & 4.9 & 4.6 & 13.1 & 13.5 & 16.4 & 14.5 \\
\hline $\mathrm{C}_{2}$ & 5.1 & 6.8 & 7.3 & 6.7 & 9.4 & 9.4 \\
\hline $\mathrm{C}_{6}$ & 6.3 & 6.7 & 6.6 & 6.5 & 8.9 & 8.4 \\
\hline
\end{tabular}

The first column refers to results 11 months, the second to 19 months after paralysis.

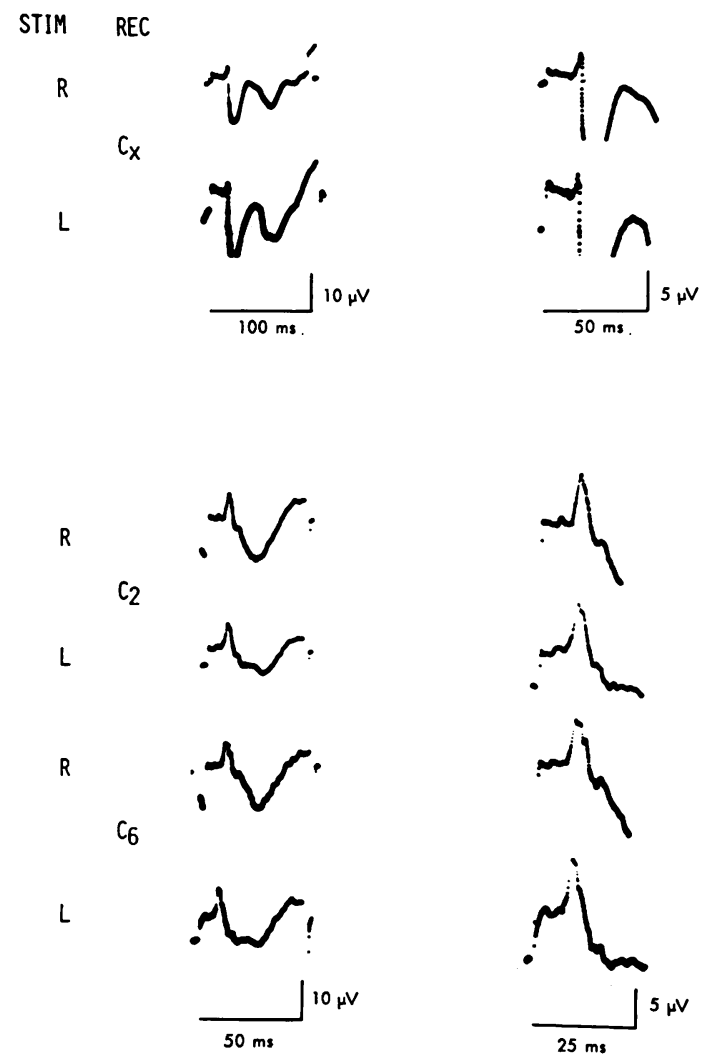

FIG. 2 Cortical somatosensory $\left(\mathrm{C}_{\mathrm{x}}\right)$ and cervical spinal cord $\left(\mathrm{C}_{2}\right.$ and $\left.\mathrm{C}_{6}\right)$ evoked potentials obtained by stimulating the right and left median nerves at the wrist.
The leg muscles were involved in eight patients, the arm muscles in four. All patients had severe and widespread weakness of muscles of one limb. Weakness was confined to one limb in eight patients, but lesser involvement of another limb occurred in two patients and of two other limbs in one patient. Six patients complained of muscular pains and five patients had meningism. No patient had objective sensory impairment. The CSF was examined shortly after onset of paralysis in all 10 patients reported by Hopkins (1974). Nine specimens had a raised white cell count and eight contained polymorphs. The highest lymphocyte count was $495 / \mathrm{mm}^{3}$ and the highest polymorph count was $75 / \mathrm{mm}^{3}$. Six specimens contained excessive protein, but the highest level was only $61 \mathrm{mg} / \mathrm{dl}$.

Without pathological information one can only infer the site of the nerve lesion producing the amyotrophy. Hopkins (1974) argues the case for a spinal cord lesion and refers to the disorder as a 'poliomyelitis-like illness'. The CSF findings and the presence of evanescent extensor plantar responses in two patients support a central pathology, but a radicular lesion with extension into the cord in some cases is equally possible. Although the distribution of amyotrophy resembles poliomyelitis, Hopkins (1974) points out that signs of meningism and muscle pain and tenderness were less prominent than in poliomyelitis. He gives little information on the longterm follow-up of his cases, but the course of recovery seen in the present case is very unlike poliomyelitis, with return of tendon reflexes and slow but gradual improvement of muscle power nine months after severe paralysis. Clinically, the lesion seems more likely to be situated in the nerve roots or brachial plexus than in the cord, the sixth and seventh cervical motor roots or the posterior cord of the brachial plexus being more severely affected than other parts. The preservation of sensation both clinically and electrophysiologically is quite compatible with nerve root or plexus lesions bearing in mind the predominance of motor signs in some neuropathies and radiculopathies and in neuralgic amyotrophy.

The nature of the amyotrophy is obscure. Poliomyelitis can be excluded on the grounds that all patients had been immunized against it and that in seven patients tested by Hopkins 
(1974) there was no rise in poliovirus antibody titres. It is most unlikely that changes in blood gases and other chemical constituents consequent on the acute asthmatic attack were responsible, for if this were the case then amyotrophy would be much more commonly seen. Unlikely also is the role of drugs administered for the asthmatic attack, for no single drug was used in all 11 cases. One may speculate on a viral or other infective cause for the amyotrophy and even for the preceding asthmatic attack; virological studies on future cases are clearly relevant. Changes in immunological and allergic responses in asthmatics may play a role, as also the administration of steroids which could interfere with the containment of a viral infection. However, only seven of the 11 patients received corticosteroids during the preceding asthmatic attack.
Finally, one may question the relevance of the asthmatic attack to the amyotrophy and ascribe it to a chance association. If this were the case, it is remarkable that Hopkins (1974) was able to collect during a six year period from the Royal Children's Hospital, Melbourne, 10 patients who presented such a stereotyped clinical picture.

I wish to thank the Department of Medical Illustration, North Staffordshire Royal Infirmary, for preparing the illustrations.

\section{REFERENCES}

Hopkins, I. J. (1974). A new syndrome: poliomyelitis-like illness associated with acute asthma in childhood. Australian Paediatric Journal, 10, 273-276.

Hopkins, I. J., and Shield, L. K. (1974). Poliomyelitis-like illness associated with asthma in childhood. Lancet, 1, 760. 